Quebec Cooperative Study

of Friedreich's Ataxia

\title{
Fatty Acid Profile of Major Lipid Classes in Plasma Lipoproteins of Patients with Friedreich's Ataxia Demonstration of a Low Linoleic Acid Content most evident in the Cholesterol-Ester Fraction
}

\author{
JEAN DAVIGNON, Y.S. HUANG, J.P. WOLF AND A.BARBEAU
}

\begin{abstract}
SUMMARY: Studies w'ere undertaken to further characterize plasma lipids and lipoprotein abnormalities in Friedreich's ataxia. The high density lipoprotein (HDL) apo AI/AII ratio w'as quantitated by densitometry and found to be normal. The free to esterified cholesterol ratio in $H D L$ was lower in Friedreich's ataxia because of a reduction in the amount of free cholesterol in this lipoprotein class. The fatty acid profile of the cholesterylester (CE) fraction was markedly deficient in linoleic acid (18:2) in both total plasma and $H D L$. There was a compensatory increase in saturated acids. The $H D L$ phospholipid (PL) fraction also show'ed a reduction in the proportion of $18: 2$ with a concomitant increase in stearic (18:0) and oleic acid (18:1) while the HDL triglyceride (TG) fraction showed only an increase in palmitoleic (16:1) and oleic acids. Feeding of soya lecithin rich in 18:2 failed to increase significantly the 18:2 content of $H D L-C E$ and $H D L-P L$ but lowered the percentage of 16:1 and 18:1 in all 3 lipid classes of HDL. Although the total plasma $C E$ fatty acid profile was perturbed in Friedreich's Ataxia, total plasma PL and
\end{abstract}

From: the Department of Lipid Metabolism and Atherosclerosis Research, and the Department of Neurobiology, Clinical Research Institute of Montreal.

Reprint requests for the entire supplement on Friedreich's Ataxia (Phase Two, Part Two) to:

Dr. André Barbeau, Clinical Research Institute of Montreal, 110 Pine Avenue West, Montreal, Quebec, Canada, H2W IR7.
TG fatty acid patterns were unaffected. Among the plasma lipoprotein fatty acid profiles, that of the low' density lipoprotein (LDL) was most affected, then that of the $H D L$. The very low density lipoprotein (VLDL) fatty acid composition showed an increase in 16:1 and a decrease in 18:2 which were entirely corrected by lecithin feeding. These results suggest the existence of a metabolic defect in the incorporation of 18:2 into chylomicron phospholipids within the intestinal mucosa.

RESUMÉ: Nous avons poursuivi notre étude de l'anomalie des lipides et des lipoprotéines plasmatiques dans l'Ataxie de Friedreich. Nous avons mesuré le rapport apo AI/AII des lipoprotéines de haute densité $(H D L)$ par densitométrie et l'avons trouvé normal. Le rapport cholestérol libre/cholestérol estérifié des $H D L$ était plus bas dans l'Ataxie de Friedreich et cela à cause surtout d'une réduction de la quantité de cholestérol libre. L'étude du profil lipidique des esters de cholestérol (CE) nous a révélé une diminution importante de la proportion d'acide linoléique (18:2) tant dans le plasma total que dans les $H D L$. Il y avait en échange une augmentation de la proportion d'acide gras saturés. Le 18:2 des phospholipides (PL) des HDL était aussi plus bas et compensé par une augmentation concomitante de l'acide stéarique (18:0) et de l'acide oléique (18:1) tandis que les triglycérides (TG) des $H D L$ étaient enrichis en acide palmitoléique (16:1) et en acide oléique. Nous avons constaté que l'addition au régime de lécithine de soya riche en 18:2 ne pouvait corriger ce déficit en 18:2 des fractions $H D L-C E$ et $H D L-P L$ alors qu'elle entrainait une diminution du pourcentage de 16:1 et de 18:1 dans les 3 classes de lipides des $H D L$. Bien que le profil d'acide gras des CE du plasma total ait été anormal dans l'Ataxie de Friedreich, cen'était pas le cas pour la composition en acide gras des PL et des TG du plasma total. Pour ce qui est du profil en acide gras des diverses fractions lipoprotéiques, il s'est avéré anormal surtout au niveau des lipoprotéines de faible densité( $L D L)$ mais aussi au niveau des $H D L$. Nous avons constaté une augmentation du 16:I et diminution du 18:2 dans les lipoprotéines de très faible densité (VLDL) que l'administration de lécithine de sov'a a complètement corrigées. Ces résultats nous suggèrent qu'il existe un bloc métabolique dans l'introduction du 18:2 dans les phospholipides des chylomicrons au niveau de la muqueuse intestinale.

\section{INTRODUCTION}

Because of known associations of neurological disorders and plasma lipid abnormalities (Steinberg, 1972; Herbert P.N., et al. 1978; Sidbury et al. 1967; Sandbank U., et al. 1971) we have carried out a systematic study of plasma lipids and lipoproteins in patients with Friedreich's ataxia (Huang Y.S., et al. 1978). This survey disclosed a low level of plasma high density lipoproteins (HDL) which had an abnormal composition, with an increased cholesterol to protein ratio. To further investigate this anomaly we measured the proportion of esterified cholesterol in the HDL fraction, used densitometry to obtain a semiquantitative appraisal of the apolipoprotein $\mathrm{AI} / \mathrm{AII}$ ratio, and examined the fatty acid pattern of $\mathrm{HDL}$ cholesteryl-esters. We found a higher proportion of cholesteryl-esters which 
were markedly deficient in linoleic acid (18:2) in the HDL of the Friedreich patients. This led us to study the fatty acid profile of the major plasma lipid classes as well as that of the various plasma lipoprotein fractions. We also examined the effect of feeding large amounts of linoleic acid-rich soybean lecithin on the compositional defect of cholesterylesters. It is the results of these studies that we wish to report here.

\section{MATERIAL AND METHODS}

\section{Subjects:}

These studies were carried out in two groups of subjects. Measurement of the proportion of free and esterified cholesterol in HDL, of the Apo $\mathrm{AI} / \mathrm{AII}$ ratio, and preliminary studies on the fatty acid pattern of HDL cholesteryl-esters (CE) were carried out on frozen aliquots obtained in our first study of-11 Friedreich's ataxia patients and 10 normolipidemic volunteers. Clinical data and details of the procedure followed to obtain the HDL fraction are given in the original study (Huang Y.S. et al., 1978).

The detailed analysis of the fatty acid patterns was carried out on fresh samples obtained in another group of 11 patients affected with Friedreich's ataxia as defined by the criteria of the Quebec Cooperative Study of Friedreich's Ataxia (QCSFA; Barbeau, 1976). There were 7 males and 4 females between the ages of 18 and 33 years. They were compared with 11 normolipidemic healthy volunteers, 6 males and 5 females, between the ages of 19 and 23 years, who were free of any neurological impairment. The characteristics of the subjects are given in table 1. The ponderal index, the plasma cholesterol levels, and the plasma phospholipid concentrations did not differ significantly between the two groups. The Friedreich patients were slightly older. Their plasma triglycerides, though well within the normal range, were significantly higher, as observed previously (Huang et al., 1978). Two women in the ataxia group had overt diabetes requiring insulin treatment, another 2 patients ( 1 male, 1 female) had an abnormal 2hour glucose tolerance test.

TABLE 1

Characteristics of Subjects Studied

\begin{tabular}{lccc}
\hline & Controls & Friedreich & p \\
\hline Number (Males) & $11(7)$ & $11(5)$ & \\
Age & $20.5 \pm 1.2^{*}$ & $26.5 \pm 3.6$ & $<0.001$ \\
Weight (kg) & $64.4 \pm 10.2$ & $56.6 \pm 5.6$ & $<0.05$ \\
Height $(\mathrm{cm})$ & $174.8 \pm 7.0$ & $164.9 \pm 10.2$ & $<0.02$ \\
Ponderal index $\dagger$ & $13.2 \pm 0.5$ & $13.0 \pm 0.7$ & $\mathrm{NS}$ \\
Cholesterol (mg/dl) & $155 \pm 23$ & $147 \pm 32$ & $\mathrm{NS}$ \\
Triglycerides (mg/dl) & $59 \pm 16$ & $116 \pm 32$ & $<0.001$ \\
Phospholipids (mg/dl) & $186 \pm 21$ & $201 \pm 43$ & $\mathrm{NS}$ \\
\hline
\end{tabular}

* mean $\pm \mathrm{SD}$; unpaired Student $t$ test used for comparisons between groups.

theight (inches) over cube roots of weight (pounds)

TABLE 2

Composition of a Commercial Soybean Lecithin Preparation

\begin{tabular}{lcrrrrr}
\hline PL Fraction: & & LPC $\dagger$ & PC & PS & PE & Total \\
\hline Phospholipids (mg/g): & & 42.3 & 198.0 & 106.0 & 185.0 & \multicolumn{1}{c}{531.3} \\
Fatty acid *(\%) & $15: 0$ & 3.17 & 0.25 & 0.75 & 0.50 & 0.13 \\
& $16: 0$ & 30.69 & 12.51 & 30.51 & 22.00 & 22.06 \\
& $16: 1$ & - & 0.26 & 0.59 & 0.48 & 0.46 \\
& $18: 0$ & 11.93 & 2.62 & 6.99 & 6.36 & 6.30 \\
& $18: 1$ & 22.49 & 6.96 & 5.09 & 8.23 & 8.15 \\
& $18: 2$ & 23.85 & 68.23 & 47.23 & 54.47 & 61.88 \\
& $18: 3$ & 2.23 & 8.71 & 7.33 & 7.19 & 8.50 \\
& $20: 2$ & 0.66 & - & 0.24 & 0.09 & 0.34 \\
& $22: 0$ & 4.17 & 0.27 & 0.68 & 0.35 & 0.18 \\
& $20: 4$ & 0.82 & 0.20 & 0.59 & 0.32 & 0.19 \\
\hline
\end{tabular}

†Abbreviations: LPC: Lysophosphatidyl-choline, PC: phosphatidyl-choline (lecithin), PS: phosphatidyl serine, PE: phosphatidyl ethanolamine.

* Fatty acids having the same retention time as standard samples of 15:0, 16:0, 16:1 etc... run on the same GLC column. See text for the names of the acids.

Five of the 11 Friedreich's ataxia patients had received large doses of soybean lecithin as part of another experimental protocol at the time of sampling. Those of us who carried out the fatty acid studies were not made aware of the actual distribution until the measurements were completed. Looking at the data of the two groups separately (i.e. with and without lecithin) allowed us to make some interesting observations. The soybean "lecithin" was obtained in a granular form from Sigma Chemical Co, StLouis, MO. It consisted of a mixture of phospholipids containing approximately $20 \%$ phosphatidyl-choline by weight. We performed a fatty acid analysis of the various phospholipid fractions (table 2). The most abundant fatty acid was linoleic acid (18:2) which was highest in the phosphatidylcholine fraction $(68.2 \%)$ and lowest in the lysophosphatidyl-choline fraction (23.9\%). The total linoleic acid content was estimated to be $230 \mathrm{mg}$ per gram of powder. The powder was also rich in palmitic acid (16:0). At the time of sampling, 3 patients had received $7.2 \mathrm{~g}$ per day over a period of 21 to 27 weeks, one had received $10.8 \mathrm{~g}$ per day over 21 weeks, and another had been given $60 \mathrm{~g}$ per day during 13 weeks. The lecithin was administered in orange juice in three divided doses.

\section{Blood sampling and separation of lipoproteins:}

Venous blood for plasma lipid determination, fatty acid analysis, and lipoprotein separation was obtained in the morning after a 12-hour fast. The 
sample was withdrawn into tubes which contained disodium EDTA (1 $\mathrm{mg}$ per milliliter of blood), immediately cooled and centrifuged at $4^{\circ} \mathrm{C}$ and processed within 24 hours. Small aliquots were used for determination of plasma cholesterol, triglyceride, and phospholipid concentrations as well as for total lipid extraction and measurement of the fatty acid profile of each lipid class. A $5 \mathrm{ml}$ aliquot was used for plasma lipoprotein separation.

The major lipoprotein fractions, very low density lipoproteins (VLDL). low density lipoproteins (LDL), and high density lipoproteins (HDL), were separated by sequential ultracentrifugation at densities 1.006, 1.063, and $1.21 \mathrm{~g} / \mathrm{ml}$ according to the technique of Havel et al. (1955). After dialysis during 24 hours against several changes of a large volume of normal saline containing EDTA $\left(10-{ }^{4} \mathrm{M}\right)$, the LDL and HDL fractions were adjusted to the original plasma volume for total lipid extraction.

The apolipoproteins of plasma HDL already separated by polyacrylamide gel electrophoresis in the first group of patients (Huang et al. 1978) using the method of Kane et al. (1973, 1975), were quantitated by densitometry of the Coomassie blue stained bands in a Vitatron Scanner, model TLD 100 (Dieren, Holland).

\section{Lipid measurements:}

The plasma cholesterol was determined on a Technicon autoanalyzer by the method of Block et al. (1966). Triglycerides were measured by the method of Laurell (1966) adapted to the autoanalyzer by $\mathrm{Kraml}$ and Cosyns (1969). Phospholipids were measured by the method of Bartlett (1959).

For the measurement of the fatty acid profile, total lipids were extracted from plasma and from the lipoprotein fractions with a chloroform/methanol mixture according to the technique of Folch et al. (1957). Aliquots of the total lipid extract were hydrolyzed at $70^{\circ} \mathrm{C}$ for 90 minutes with $1 \mathrm{~N} \mathrm{KOH}$ in a $70 \%$ methanol solution. After removing the non-saponifiable material by hexane extraction (equal volumes, 3 times), the remaining aqueous phase was acidified with $10 \mathrm{~N}$ $\mathrm{HCl}$. The fatty acids were then extracted into hexane.

Separate aliquots of the total lipid extract were fractionated by thin layer chromatography (TLC) on Silica Gel H-coated $(0.5 \mathrm{~mm}$ thick) $20 \times 20 \mathrm{~cm}$ glass plates. The plates were developed with hexane/diethyl ether/acetic acid 40:10:1 volume. Cholesteryl-esters (CE), triglycerides (TG), and phospholipids (PL) were visualized by spraying with a $0.1 \%$ solution of 2,7 -dichlorofluorescein (Brinkmann Instruments), Rexdale, Ontario). The bands corresponding to TG and PL were scraped into a test tube and $2.0 \mathrm{ml}$ of boron trifluoride-methanol reagent (Matheson Coleman \& Bell Manufacturing Chemists, Norwood, $\mathrm{OH}$ ) was added and heated in boiling water for 30 and 90 minutes respectively (Morrison and Smith, 1964). The CE fraction scraped off the plate was first saponified as for total lipids and the free cholesterol extracted before methylation of the fatty acids with $\mathrm{BF}_{3}$-methanol. The methyl esters in all cases were extracted into hexane and concentrated under a stream of nitrogen for gas liquid chromatography (GLC).

GLC of the methylated fatty acids was performed on a 6-foot U-shaped glass column ( $3 \mathrm{~mm}$ i.d.) packed with $10 \%$ Silar $10 \mathrm{C}$ on $100-120$ mesh Gas Chrom Q (Applied Science Laboratories Inc. State College, PA) at $185^{\circ} \mathrm{C}$ using a Hewlett-Packard F \& M model 402 apparatus equipped with an hydrogen flame ionization detector. The hydrogen flow rate was adjusted at $35 \mathrm{ml}$ per min. An electronic integrator (Hewlett-Packard 3373B) was used to measure the relative proportion of the various fatty acids. Retention times were compared with those of methylated standards purchased from Applied Science (L205, L-206, L-207, L-209 and KD mixtures).

To measure the relative proportion of free (FC) and esterified cholesterol in the first group of patients, an aliquot of the HDL total lipid extract was separated by TLC as above. The



Figure 1 - Fatty acid profile of cholesteryl-esters in high density lipoproteins of normal subjects (shaded bars) and of Friedreich's ataxia patients (dotted lines, F), a preliminary experiment on frozen aliquots. $\mathrm{C}$ indicates the number of carbon atoms in the fatty acids, $\Delta$ gives the number of double bonds; $20: 4$ represents here the pooled long chain fatty acids of retention times equal to or greater than arachidonic acid. 
FC and CE bands were recovered and placed in a test tube containing $0.1 \mathrm{mg}$ $5 \alpha$-cholestane as internal standard. They were saponified with $1 \mathrm{~N} \mathrm{KOH}$ in a $70 \%$ methanol solution at $70^{\circ} \mathrm{C}$ for 90 minutes, the cholesterol was extracted into hexane which was evaporated to dryness. The trimethylsilyl-derivatives (TMS) were prepared (Marcel and Vezina, 1973) and measured by GLC on a 4-foot column packed with $3 \%$ OV-1 on $80-100$ mesh Chromosorb W (Applied Science) at $245^{\circ} \mathrm{C}$ with an hydrogen flow rate of $30 \mathrm{ml}$ per minute.

\section{RESULTS}

The proportion of esterified cholesterol was greater in the Friedreich's ataxia patients (84.14 $2.20 \%$, mean \pm SD) than in the control subjects $(79.69 \pm 3.58 \%)$ and the difference was statistically significant $(p<0.01)$. The percentages of free cholesterol were thus respectively 15.86 and 20.31. Expressed as percentage of the total HDL molecule there was $3.2 \%$ of FC and $17.1 \%$ of $\mathrm{CE}$ in the ataxic patients as compared to $2.8 \%$ of FC and $11.0 \%$ of $\mathrm{CE}$ in the controls. In absolute values, however, the difference is mainly related to a reduction the total amount of HDL free cholesterol. The HDL-FC concentration was $4.85 \pm 1.22$ $\mathrm{g} / \mathrm{dl}$ in the patients and $7.00 \pm 1.80$ in the controls, a significant difference $(\mathrm{p}<0.01)$. In contrast, the HDL-CE levels were $25.69 \pm 4.01$ in Friedreich's ataxia and $27.30 \pm 5.45 \mathrm{mg} / \mathrm{dl}$ in the controls (NS).

The densitometric measurement of the AI/AII ratio did not disclose any difference between the two groups. It averaged $4.18 \pm 1.24$ in the control subjects and $4.05 \pm 0.95$ in the patients.
FATTY ACID COMPOSITION

\section{OF TOTAL PLASMA LIPIDS FRACTIONS}


Figure 2-Fatty acid profiles of total plasma cholesterol esters (CE) phospholipids (PL) and triglycerides. $C$ indicates chain length (number of carbon atoms), $\triangle$ gives the number of double bonds.
FATTY ACID COMPOSITION

\section{OF PLASMA LIPOPROTEIN FRACTIONS}

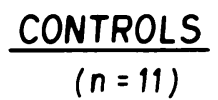

$\% \quad V L D L$

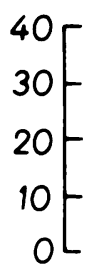

FRIEDREICH $(n=11)$

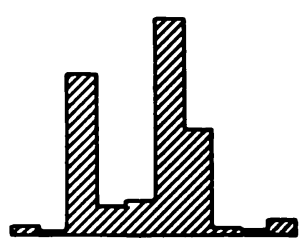

LDL
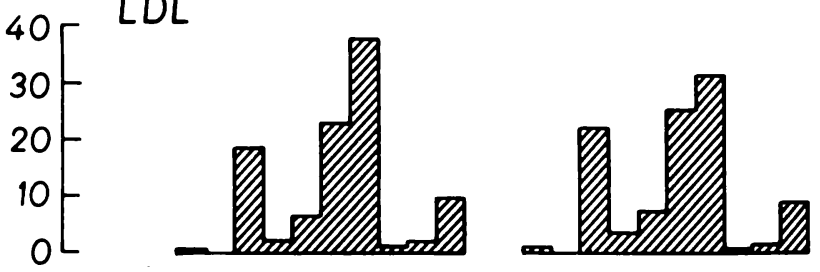

HDL


Figure 3-Fatty acid profiles of the total lipid extract of plasma very low density lipoproteins (VLDL), low density lipoproteins (LDL) and high density lipoproteins (HDL). C indicates chain length (number of carbon atoms) and $\Delta$ the number of double bonds. 
The abnormalities found in the CE/FC ratio coupled with the lack of obvious differences in the protein moiety of the HDL fraction led us to examine the fatty acid composition of the $C E$ fraction on frozen aliquots of the HDL obtained in the course of our previous study (Huang et al., 1978). The results of this preliminary experiment are depicted in figure 1. The fatty acid composition of the HDL-CE in the normolipidemic volunteers are represented by the shaded bars and contrasted with the measurements made in the Friedreich's cases (dotted lines). The most obvious difference was in the linoleic acid content which was significantly lower in Friedreich's ataxia $(28.07 \pm 4.29$ vs $47.87 \pm 6.67 \%$, $\mathrm{p}<0.001)$. This difference was compensated by a relative increase in the other fatty acids especially of longer chain length, although the individual variations were quite pronounced at this end of the scale.

We then turned to a new group of patients to explore these abnormalities in depth with fresh plasma. First, we looked separately at the major plasma lipid classes to determine whether HDL-CE abnormality was also present in the total CE fraction of plasma and whether it could be detected also in total plasma triglycerides and phospholipids. The results are presented in figure 2 . In Friedreich's ataxia the fatty acid profile of the cholesteryl-ester fraction was markedly modified whereas that of the other two lipid classes were unchanged. There again the proportion of 18:2 was strikingly lower than normal $(29.11 \pm 6.09 \%$ vs $45.50 \pm 9.67 \%, p<0.001)$. In contrast, the percentage of stearic acid (18:0) was higher $(4.60 \pm 2.19$ vs $2.13 \pm 0.70$, $\mathrm{p}<0.01)$ as well as the percentage of eicosa-trienoic acid $(20: 3)(5: 49 \pm 3.94$ vs $1.75 \pm 0.88, \mathrm{p}<0.01$ ) and of fatty acids with a retention time longer than that of arachidonic acid (20:4) $(1.75 \pm 2.65$ vs $6.11 \pm 4.78, \mathrm{p}<0.02)$. Arachidonic acid itself was lower in Friedreich's ataxia (1.11 \pm 0.66 vs $3.36 \pm 2.13)$. These differences in the fatty acid profile of plasma cholesteryl-esters were not modified by lecithin supplementation and values for the treated group were virtually identical to those of the untreated groups. For the other plasma lipid classes, there were no significant differences between control subjects and Friedreich's ataxia patients. There was a non significant increase in the 18:2 content of the triglyceride fraction with lecithin treatment in the
Friedreich group $(6.48 \pm 2.55$ vs $9.07 \pm 2.24$ for a control value of $9.48 \pm 3.66 \%$ ). Such a trend was not seen for the 18:2 content of the phospholipid fraction.

Next, we looked at the total fatty acid profile of the various lipoprotein fractions in search of an abnormality which would be specific for a given lipoprotein class. The results of these measurements are given in table 3 . There were no differences between control subjects and Friedreich's ataxia patients in the VLDL fatty acid pattern. In the LDL fraction, the proportion of 18:2 was significantly reduced in Friedreich's ataxia whereas that of 14:0 (myristic acid) and 16:0 (palmitic acid) were significantly increased. The HDL fatty acid profile was also perturbed: 14:0, 16:0 (palmitic acid) and 16:1 (palmitoleic acid) percentages were significantly higher whereas the percentage of 18:0 was significantly lower in the Friedreich cases. The proportion of 18:2 was also reduced but the differences did not reach statistical significance because of one outlier. In all lipoprotein classes, there was a nonstatistically significant trend for 20:4 to be lower in the patients than in the controls. When the treated and

TABLE 3

Percent Fatty' Acid Composition of Major Plasma Lipoprotein Classes

\begin{tabular}{c|rr|rr|rr}
\hline \multirow{2}{*}{$\begin{array}{c}|c| \\
\text { Fatty }\end{array}$} & \multicolumn{2}{c|}{ LDL } & \multicolumn{2}{c}{ HDL } \\
Acid* & Control (11) & Friedreich (11) & Control (11) & Friedreich (11) & Control (11) & Friedreich (11) \\
\hline $14: 0$ & $1.43 \pm 0.46 \dagger$ & $1.61 \pm 0.95$ & $0.29 \pm 0.13$ & $0.52 \pm 0.30^{\mathrm{c}}$ & $0.11 \pm 0.06$ \\
$14: 1$ & $0.33 \pm 0.14$ & $0.28 \pm 0.14$ & $0.16 \pm 0.08$ & $0.18 \pm 0.12$ & $0.46 \pm 0.27^{\mathrm{d}}$ \\
$16: 0$ & $25.92 \pm 2.02$ & $27.83 \pm 3.43$ & $17.98 \pm 1.17$ & $21.91 \pm 2.30^{\mathrm{d}}$ & $19.53 \pm 1.50$ & $23.75 \pm 2.66^{\mathrm{d}}$ \\
$16: 1$ & $4.00 \pm 1.08$ & $4.99 \pm 1.38$ & $2.42 \pm 0.75$ & $3.11 \pm 1.15$ & $1.71 \pm 0.42$ & $2.43 \pm 0.86^{\mathrm{c}}$ \\
$18: 0$ & $5.56 \pm 1.31$ & $5.73 \pm 1.03$ & $6.20 \pm 0.50$ & $6.93 \pm 1.12$ & $10.03 \pm 0.71$ & $9.27 \pm 0.59^{\mathrm{d}}$ \\
$18: 1$ & $37.88 \pm 2.77$ & $37.32 \pm 3.44$ & $22.98 \pm 1.98$ & $24.89 \pm 3.32$ & $19.20 \pm 1.27$ & $19.79 \pm 2.44$ \\
$18: 2$ & $20.35 \pm 3.64$ & $18.33 \pm 6.57$ & $37.58 \pm 3.75$ & $31.33 \pm 6.25$ & $32.32 \pm 4.07$ & $28.98 \pm 5.01$ \\
$18: 3-20: 2$ & $0.67 \pm 0.61$ & $1.10 \pm 0.46$ & $0.80 \pm 0.29$ & $0.85 \pm 0.20$ & $1.11 \pm 1.09$ & $0.64 \pm 0.14$ \\
$20: 3$ & $0.45 \pm 0.33$ & $0.54 \pm 0.22$ & $1.45 \pm 0.68$ & $1.36 \pm 0.46$ & $2.11 \pm 0.47$ & $2.12 \pm 1.11$ \\
$20: 4$ & $3.38 \pm 1.63$ & $2.91 \pm 0.80$ & $9.68 \pm 1.69$ & $8.46 \pm 2.00$ & $13.27 \pm 1.84$ & $11.76 \pm 2.04$ \\
$>20: 4$ & - & - & $0.46 \pm 0.24$ & $0.38 \pm 0.17$ & $0.54 \pm 0.14$ \\
\hline
\end{tabular}

* see table 2 .

$\dagger$ mean $\pm \mathrm{SD}$, statistical comparisons using unpaired Student $t$ test

$\mathrm{p}<0.01$

$\mathrm{p}<0.02$

$\mathrm{p}<0.05$

$\mathrm{p}<0.001$ 
untreated subgroups were compared, it was found that none of these changes could be accounted for by lecithin feedings. Indeed, exclusion from the calculations of the treated patients made the differences with the control group even more evident. In contrast, the lecithin feeding had corrected a higher level of $16: 1 \quad(5.92 \pm 1.10$ vs $3.88 \pm 0.67, \mathrm{p}<0.01)$ and a lower proportion of $18: 2$ (15.72 \pm 2.84 vs. $21.46 \pm 4.42, \mathrm{p}<0.05)$ in the VLDL fraction of the untreated patients.

We then focused our attention upon the HDL fraction and measured the fatty acid pattern in each major esterified lipid class. The results for the cholesteryl-esters are presented in table 4 for the control subjects, the entire group of Friedreich patients, as well as for the lecithin-treated and untreated subgroups. The most striking difference is again in the 18:2 component which is $40 \%$ lower and in the 18:0 fraction which is more than doubled in the Friedreich's ataxia patients. These differences, also noted with the untreated subgroup, are not altered by lecithin feeding. In contrast, the $25 \%$ higher $16: 0$ is entirely accounted for by lecithin feeding. There is finally a higher, though not statistically significant, percentage of 14:0 in all Friedreich groups. The fatty acid composition of the HDL phospholipids is given in table 5. It shows a markedly lower 18:2 content and a higher 18:0 percentage which are not appreciably modified by lecithin feeding. In contrast, the higher values of 18:1 in the Friedreich group are in part accounted for by lecithin supplementation. Lecithin feeding also tended to lower 20:40. Table 6 finally summarizes the findings for HDL-TG fatty acid composition. There is a higher percentage of 16:1 which seems to be part of the Friedreich's ataxia pattern and is completely corrected by lecithin administration. The proportion of oleic acid (18:1) is also higher but only partly corrected by lecithin feedings. The 18:2 content tends to be higher in all Friedreich groups but the difference is small (15\%) and not statistically significant. The fatty acid of the 20:3-20:4 region also tends to be lower in the Friedreich's ataxia patients.

\section{DISCUSSION}

The abnormal cholesterol to protein ratio in the plasma HDL fraction of the Friedreich's ataxia patients previously reported (Huang et al., 1978) could have reflected a disturbance in the composition of either the protein or the lipid portion of the molecule. Visual comparison of the HDL apolipoprotein patterns on polyacrylamide gel had failed to disclose any major difference between the control samples and those of the

TABLE 4

Percent Fatty Acid Composition of HDL Cholesterol Esters

\begin{tabular}{ccccc}
\hline & \multicolumn{3}{c}{ Friedreich } \\
\hline Fatty Acid * $^{\text {Controls (11) }}$ & All (11) & Untreated (6) & Treated (5) $\dagger$ \\
\hline $14: 0$ & $1.23 \pm 0.54$ & $2.58 \pm 0.86^{\mathrm{a}}$ & $2.35 \pm 0.82^{\mathrm{b}}$ & $2.87 \pm 0.90^{\mathrm{a}}$ \\
$16: 0$ & $20.63 \pm 4.16$ & $25.71 \pm 4.16$ & $23.47 \pm 4.17$ & $28.41 \pm 2.23^{\mathrm{bc}}$ \\
$16: 1$ & $2.29 \pm 0.89$ & $2.47 \pm 1.11$ & $3.23 \pm 0.78$ & $1.56 \pm 0.65^{\mathrm{d}}$ \\
$18: 0$ & $3.33 \pm 1.78$ & $7.21 \pm 1.35^{\mathrm{a}}$ & $6.36 \pm 1.04^{\mathrm{b}}$ & $8.23 \pm 0.92^{\mathrm{ac}}$ \\
$18: 1$ & $19.93 \pm 3.91$ & $21.98 \pm 3.53$ & $23.43 \pm 2.79$ & $20.25 \pm 3.82$ \\
$18: 2$ & $45.18 \pm 6.12$ & $26.78 \pm 4.68^{\mathrm{a}}$ & $27.43 \pm 4.46^{\mathrm{a}}$ & $26.02 \pm 5.34^{\mathrm{a}}$ \\
n.i.§ & $2.54 \pm 1.20$ & $3.04 \pm 1.17$ & $3.19 \pm 1.60$ & $2.87 \pm 0.44$ \\
$20: 3-20: 4$ & $4.63 \pm 2.30$ & $5.54 \pm 2.36$ & $6.17 \pm 2.62$ & $4.77 \pm 2.00$ \\
$>20: 4$ & trace & $1.60 \pm 1.34$ & $1.09 \pm 0.81$ & $2.15 \pm 1.71$ \\
\hline
\end{tabular}

* see table 2

$\dagger$ dietary supplement of soybean lecithin

$\mathrm{p}<0.001$ as compared with control group

b $\mathrm{p}<0.01$ as compared with control group

$c \mathrm{p}<0.05$ as compared with untreated group

00.01 as compared with untreated group

e $\mathrm{p}<0.02$ as compared with untreated group

$\S$ n.i.: not identified

TABLE 5

Percent Fatty Acid Composition of HDL Phospholipids

\begin{tabular}{ccccc}
\hline & & \multicolumn{3}{c}{ Friedreich } \\
\hline Fatty Acid * & Controls (11) & All (11) & Untreated (6) & Treated (5) $\dagger$ \\
\hline $16: 0$ & $31.26 \pm 4.31$ & $33.32 \pm 3.93$ & $32.01 \pm 4.30$ & $34.89 \pm 3.13$ \\
$16: 1$ & n.d.§ & $0.57 \pm 0.50$ & $0.87 \pm 0.48$ & $0.21 \pm 0.19$ \\
$18: 0$ & $11.82 \pm 3.60$ & $17.03 \pm 2.32^{\mathrm{a}}$ & $15.87 \pm 2.38^{\mathrm{c}}$ & $18.42 \pm 1.38^{\mathrm{b}}$ \\
$18: 1$ & $13.15 \pm 1.58$ & $15.40 \pm 2.52^{\mathrm{c}}$ & $16.15 \pm 1.48^{\mathrm{b}}$ & $14.52 \pm 3.36$ \\
$18: 2$ & $28.38 \pm 4.04$ & $19.28 \pm 3.02^{\mathrm{a}}$ & $18.47 \pm 3.17^{\mathrm{a}}$ & $20.25 \pm 2.84^{\mathrm{a}}$ \\
n.i.§ & $0.76 \pm 0.29$ & $0.58 \pm 0.23$ & $0.59 \pm 0.20$ & $0.56 \pm 0.28$ \\
$20: 3$ & $2.61 \pm 1.19$ & $3.39 \pm 1.04$ & $3.95 \pm 1.10$ & $2.72 \pm 0.41$ \\
$20: 4$ & $11.86 \pm 4.21$ & $9.68 \pm 2.42$ & $11.02 \pm 2.49$ & $8.08 \pm 1.00$ \\
$>20: 4$ & n.d. & $0.49 \pm 0.40$ & $0.68 \pm 0.44$ & $0.26 \pm 0.19$ \\
\hline
\end{tabular}

* see table 2.

†dietary supplement of soybean lecithin

$\$$ n.i.: not identified; n.d.: not detectable

${ }^{a} \mathrm{p}<0.001$ as compared with control group

" $\mathrm{p}<0.01$ as compared with control group

c $\mathrm{p}<0.05$ as compared with control group patients (Huang et al., 1978). Since the apo AI/AII ratio may change the lipids (Cheung and Albers, 1977) we quantitated this ratio by densitometry. These measurements failed to demonstrate any difference. Although the proportion of AI was slightly overestimated because of the close proximity of the slower migrating and much smaller apo $\mathrm{E}$ band, the results obtained by our procedure compare well with those obtained by more affinity of the molecules for certain 
TABLE 6

Percent Fatty Acid Composition of HDL Triglycerides

\begin{tabular}{crrrr}
\hline & & \multicolumn{3}{c}{ Friedreich } \\
\hline Fatty Acid * & Controls (9) & \multicolumn{1}{c}{ All (11) } & Untreated (6) & Treated (5) $\dagger$ \\
\hline$<16: 0$ & $2.75 \pm 0.93$ & $3.02 \pm 1.22$ & $2.95 \pm 1.18$ & $3.09 \pm 1.40$ \\
$16: 0$ & $45.45 \pm 5.78$ & $47.57 \pm 4.80$ & $46.07 \pm 5.49$ & $49.37 \pm 3.53$ \\
$16: 1$ & $1.31 \pm 0.48$ & $2.46 \pm 1.22^{\mathrm{b}}$ & $3.13 \pm 1.29$ & $1.65 \pm 0.42^{\mathrm{c}}$ \\
$18: 0$ & $13.48 \pm 5.05$ & $10.22 \pm 2.41$ & $9.77 \pm 2.90$ & $10.77 \pm 1.82$ \\
$18: 1$ & $13.82 \pm 2.83$ & $20.54 \pm 5.04^{\mathrm{a}}$ & $23.55 \pm 4.87$ & $16.92 \pm 1.97^{\mathrm{b}}$ \\
n.i. $\$$ & $1.87 \pm 1.02$ & $1.95 \pm 1.11$ & $1.18 \pm 0.71$ & $2.87 \pm 0.69^{\mathrm{d}}$ \\
$18: 2$ & $4.86 \pm 4.82$ & $5.99 \pm 1.49$ & $5.98 \pm 1.76$ & $6.00 \pm 1.31$ \\
n.i. & $2.08 \pm 0.94$ & $1.82 \pm 1.03$ & $1.32 \pm 0.89$ & $2.43 \pm 0.91$ \\
$20: 3-20: 4$ & $13.45 \pm 7.40$ & $5.97 \pm 3.09$ & $5.58 \pm 3.05$ & $6.44 \pm 3.42$ \\
$>20: 4$ & $0.92 \pm 0.87$ & $0.46 \pm 0.28$ & $0.48 \pm 0.35$ & $0.44 \pm 0.21$ \\
\hline
\end{tabular}

* see table 2.

+ dietary supplement of soybean lecithin

$\S$ n.i.: not identified

$\mathrm{p}<\mathbf{0 . 0 0 1}$, comparison with control group

$b<0.02$, comparison with control group

$c \mathrm{p}<0.05$, comparison with untreated group

$p<0.01$, comparison with untreated group

$\because$

accurate techniques. Calculations from the data of Cheung and Albers (1977), who used a specific and sensitive immunoassay, indicate a mean value of $3.76 \pm 0.21$ for males $(n=6)$ and $4.07 \pm 0.34$ for females $(n=6)$. Our own values were virtually identical: $3.79 \pm 0.84$ for males $(n=4)$ and $4.24 \pm 1.02$ for females $(n=6)$ in the normal group and respectively $4.02 \pm 1.48(n=5)$ and $4.35 \pm 1.09(n=5)$ in the Friedreich group. The slightly higher figures for the males in the Friedreich's ataxia patients are not statistically different from control values. Thus, there were no gross abnormality in the protein moiety of the HDL.

We had shown that the plasma HDL-protein concentration was considerably lower in Friedreich's ataxia while the HDL cholesterol concentration was closer to normal (Huang et al., 1978). The present study reveals that the proportion of free cholesterol is markedly reduced relative to the cholesteryl-esters in HDL, another finding which directs our attention towards the HDL-CE fraction in a search for potential anomalies.

Since the degree of saturation of lipids transported by a lipoprotein has been shown to affect both its metabolism and its lipid carrying capacity (Shepherd et al., 1978; Spritz and Mishkel, 1969), it was of interest to examine the fatty acid composition of the various plasma lipids and lipoprotein classes. A preliminary study carried out on the HDL-CE, a fraction most likely to be affected in view of our previous findings, revealed a striking reduction in the proportion of linoleic acid.

Each major plasma lipid class has its own distinctive fatty acid profile which is known to be maintained across the various lipoprotein fractions (Goodman and Shiratori, 1964). The fatty acid profiles of CE, PL, and TG of our control subjects are in close agreements with those reported in the literature (Goodman and Shiratori, 1964) for both the total plasma (figure 2) and the HDL fraction (table 4). Of the 3 lipid classes, only cholesterylester fatty acid pattern was grossly altered in Friedreich's ataxia.

Table 2 reveals that a distinctive pattern also exists for each lipoprotein fraction taken separately. This is most obvious when displayed in a graphic form as seen in figure 3. It can be seen readily that the LDL pattern is the most markedly affected in Friedreich's ataxia while the fatty acid profile of the HDL is less perturbed and that of the VLDL is unchanged. The lower 18:2, 18:0, and 20:4 fractions and the higher 14:0, 16:0, and 16:1 fatty acids in HDL, as well as the lower LDL 18:2 and 20:4 and higher LDL 14:0 and 16:0 fractions in Friedreich's ataxia were not related to lecithin feeding of a subgroup of the patients. In contrast, a closer look at the VLDL changes revealed that dietary lecithin supplementation had corrected an increase in 16:1 and a decrease in 18:2 in this lipoprotein class.

A detailed analysis of the various lipid classes of the HDL fraction revealed the most striking changes in fatty acid composition. Whereas the major changes in total plasma lipid classes had been exclusively in the CE component, all 3 fractions, CE, PL and TG, were markedly altered in HDL. The reduction in 18:2 CE was of the same order of magnitude in HDL (39.4\%) as that in plasma CE (37.1\%). This was accompanied by a compensatory increase in 14:0 and 18:0 (table 4). The HDL phospholipids had a $32 \%$ lower content of 18:2, a $44 \%$ higher content of 18:0, and a $12.5 \%$ higher proportion of 18:1 (table 5). In the HDL-TG fraction, 16:1 and 18:1 were higher in the Friedreich patients by $88 \%$ and $48.6 \%$ respectively. Lecithin feeding failed to increase significantly the 18:2 content of HDL-CE and HDL-PL, although it could bring down the percentage of $16: 1$ and 18:1 in all 3 lipid classes of HDL.

One way to reconcile these findings is by postulating a block in the incorporation of 18:2 into chylomicron phospholipids at the intestinal wall level. According to Tall and Small (1978), the HDL phospholipids would originate from the surface components of chylomicrons. A metabolic defect in phosphatidyl-choline (PC) esterification in the enterocyte would bring into plasma HDL 18:2-deficient PC molecules. The circulating lecithin: cholesterol-acyl-transferase (LCAT) enzyme would then be presented with a poor substrate and be unable to transfer normal amounts of 18:2 from the 2 position of $P C$ to the HDL cholesteryl-esters which would in turn be deficient in 18:2. Exchange with other lipoproteins would allow their CE fraction to reflect this abnormal composition. Since $60 \%$ of erythrocyte membrane PC is exchangeable (Reed, 1968) and since the transfer of 
phospholipids from plasma lipoproteins to red blood cell membrane constitutes a major pathway for the removal of erythrocyte PL and is independent of the degree of saturation of their fatty acids (Renooij and Van Golde, 1977) we would expect the membrane phospholipids to reflect the abnormal fatty acid profile described above.

If the 18:2 molecules provided by the intestinal hydrolysis of lecithin behave in the same manner as 18:2 molecules derived from the hydrolysis of polyunsaturated fatty acids (Shepherd et al., 1978) we would expect an enrichment of all HDL lipoprotein fractions in 18:2 upon feeding lecithin. There is evidence for that in a recent publication of Rossieneu et al. (1979). The feeding of polyunsaturated lecithin to chimpanzees was found to raise the 18:2 content of $\mathrm{HDL}_{3}$. This increase was especially striking in the $\mathrm{HDL}_{3}-\mathrm{PL}$ fraction (from 18.7 to $32.2 \%$ ). The fact that dietary lecithin supplementation failed to enrich either HDL-PL or HDL-CE in 18:2 is in favor of our hypothesis. Indeed, the patient who received the largest amount $(60 \mathrm{~g}$ per day) of the lecithin preparation had higher than control 18:2 values in all the lipid fractions studied except in the total plasma CE (20.8 vs $45.5 \%$ ), in HDL-CE (33.8 vs $45.2 \%)$, and in HDL-PL (24.8 vs $28.4 \%$ ). This patient was the outlier mentioned above in relation with the HDL total fatty acid pattern. That lecithin feeding could enrich VLDL fatty acids in 18:2 and increase to some extent the 18:2 content of HDL-TG, would suggest conversely that their 18:2 molecules did not follow the same metabolic pathway.

Whether the defect responsible for the 18:2 deficiency in plasma CE and HDL-PL fractions is related to the pathogenesis of Friedreich's ataxia remains to be determined. That a defect in HDL composition might be related to neurological manifestations has been discussed by Scanu (1978). There are neurological manifestations in Tangier disease where HDL are deficient, of abnormal composition, and their metabolism perturbed (Schaefer et al., 1978). The HDL of abetalipoproteinemia, where ataxia is a prominent feature, are also abnormal. Indeed, as in Friedreich's ataxia, their total amount is reduced, their content of 18:2 is decreased and their CE/FC ratio is abnormal (Scanu, 1978). It is possible that the defect reported here is not specific for Friedreich's ataxia. Indeed, a reduction in 18:2 has been reported in the fatty acid composition of total plasma lipids in multiple sclerosis and other neurological diseases (Baker et al., 1963; Kalofoutis and Jullien, 1974). Yao et al. (1976) have conducted an analysis of serum non polar lipids in a series of hereditary neuropathies. In most of them, they found a significant decrease in the percentage of linoleate to total fatty acids in both CE and TG. These changes were observed in hereditary motor neuropathy, neuronal Charcot-Marie-Tooth disease, Dejerine-Sottas disease, and in 6 cases of Friedreich's ataxia. They did not study the individual plasma lipoproteins and their lipid components. On the other hand, they examined the fatty acid profile of plasma nonesterified fatty acids, which we have not done, and reported a significant increase in 16:1 in Friedreich's ataxia. Though not necessarily specific for Friedreich's ataxia, it remains that the postulated defect might contribute to the phenotypic expression in several of these neurological diseases.

If the hypothesis of a defect in PC esterification at the enterocyte level is true, we would expect LCAT activity to be somewhat reduced because of the abnormal substrate. The slightly lower but not significantly different values reported for LCAT activity in Friedreich's ataxia as compared to healthy subjects $(83 \pm 7$ vs $97 \pm 19$ $\mathrm{mmol} / \mathrm{ml} / \mathrm{hr}$ ) (Yao et al. 1976) would be in accordance with this view. It would be important, however, to determine whether this lowered activity could be enhanced in the presence of a normal substrate.

\section{ACKNOWLEDGEMENTS}

This work was supported by the "Association Canadienne de l'Ataxie de Friedreich", the Medical Research Council of Canada, and the Quebec Heart Foundation.

The authors wish to thank Mr. Michel Tremblay, Miss Lucie Boulet, and Miss Murielle Paquette for their skilfull technical assistance. They are grateful to
Miss Danièle Bédard R.N. and Miss Suzette Doyon R.N. for their help with the patients and to Mrs. Réjeanne Ouellet for typing the manuscript.

\section{REFERENCES}

BAKER, R. W. R., THOMPSON, R. H.S. and ZILKHA, K. J. (1963). Fatty acid composition of brain lecithins in multiple sclerosis. Lancet 1, 26-27.

BARBEAU, A. (1976). Fried reich's ataxia 1976 An overview. Can. J. Neurol. Sci. 3, 389-397.

BARTLETT, G. R. (1959). Phosphorus assay in column chromatography. J. Biol. Chem. 234, 466-468.

BLOCK, W. D., JARRETT, K. J., and LEVINE, J. B. (1966). An improved automated determination of serum total cholesterol with a single color reagent. Clin. Chim. 12, 681-689.

CHEUNG, M. C. and ALBERS, J. J. (1977). The measurement of apolipoprotein $\mathrm{AI}$ and All levels in men and women by immunoassay. J. Clin. invest 60, 43-50.

FOLCH, J., LEES, M., and SLOANESTANLEY, G. H. (1957). A simple method for the isolation and purification of total lipids from animal tissues. J. Biol. Chem. 226, 497-509.

GOODMAN, D. S. and SHIRATORI, T. (1964). Fatty acid composition of human plasma lipoprotein fractions. J. Lipid Res. 5, 307-313.

HAVEL, R. J., EDER, H. A. and BRAGDON, J. H. (1955). The distribution and chemical composition of ultracentrifugally separated lipoproteins in human serum. J. Clin. Invest. 34, 1345-1353.

HERBERT, P. N., GOTTO, A. G., and FREDRICKSON, D. S. (1978). Familial lipoprotein deficiency (abetalipoproteinemia, hypobetalipoproteinemia and Tangier disease). In: The metabolic basis of inherited disease. 4th edition, (Stanbury, J. B., Wyngaarden, J. B. and Fredrickson, D. S. eds). McGraw-Hill, New York, pp. 544-588.

HUANG, Y. S., NESTRUCK, A. C.. BARBEAU, A., BOUCHARD, J. P. and DAVIGNON, J. (1978). Plasma lipids and lipoproteins in Friedreich's ataxia and familial spastic ataxia - Evidence for an abnormal composition of high density lipoproteins. Can. J. Neurol. Sci. 5, 149-156.

KALOFOUTIS, A. and JULLIEN, G. (1974). A study of serum fatty acids in neurological diseases. Biochimie 56, 623-624.

KANE, J. P. (1973). A rapid electrophoretic technique for identification of subunit species of apoprotein in serum lipoproteins. Anal. Biochem. 53, 350-364.

KANE, J. P., SATA, T., HAMILTON, R. L. and HAVEL, R. J. (1975). Apoprotein composition of very low density lipoproteins of human serum. J. Clin. Invest. 56, 16221634.

KRAML, N. and COSYNS, L. (1969). A semiautomated determination of serum triglycerides. Clin. Biochem. 2, 373-380. 
LAURELL, S. (1966). Method for routine determination of plasma triglycerides. Scand. J. Clin. Lab. Invest. 18, 668-672.

MARCEL, Y. L. and VEZINA, C. (1973). A method for the determination of the initial rate of reaction of lecithin: cholesterol acyltransferase in human plasma. Biochim. Biophys. Acta 306, 497-504.

MORRISON, W. R. and SMITH, L. M. (1964), Preparation of fatty acid methyl esters and dimethylacetals from lipids in the boron fluoride-methanol. J. Lipid Res. 5, 600-608.

REED, C. F. (1968). Phospholipid exchange between plasma and erythrocytes in man and the dog. J. Clin. Invest. 47, 749-760.

RENOOIJ, W. and VAN GOLDE, L. M. G (1977). The transposition of molecular classes of phosphatidylcholine across the rat erythrocyte membrane and their exchange between the red cell membrane and plasma lipoproteins. Biochim. Biophys. Acta 470, 465-474.
ROSSENEU, M., DECLERCQ, B.,VANOAMME, D., VERCAEMST, R., SOETEWEY, F., PEETERS, $H$. and BLATON, $V$. (1979). Influence of oral polyunsaturated and saturated phospholipid treatment on the lipid composition and fatty acid profile of chimpanzee lipoproteins. Atherosclerosis $32,141-153$.

SANDBANK, U., BECHAR, M. and BORNSTEIN, B. (1971). Hyperlipemic polyneuropathy. Acta Neuropath. 19, 290-300.

SCANU, A. M. (1978). Abetalipoproteinemia and hypobetalipoproteinemia: what is the primary defect? Advances Neurol. 21, 125130.

SCHAEFER, E. J., BLUM, C. B., LEVY, R. I., JENKINS, L. L., ALAUPOVIC, P., FOSTER, D. M., BREWER, H. B. Jr. (1978). Metabolism of high-density lipoprotein apolipoproteins in Tangier disease. New Engl. J. Med. 299, 905-910.

SHEPHERD, J., PACKARD, C. J., PATSCH, J. R., GOTTO, A. M., Jr. and TAUNTON O. D. (1978). Effects of dietary polyunsaturated and saturated fat on the properties of high density lipoproteins and the metabolism of apolipoprotein AI. J. Clin. Invest. 61, 1582-1592.
SIDBURY, J. B. Jr., SMITH, E. K. and HARLAN, W. (1967). An inborn error of short-chain fatty acid metabolism. J. Pediatrics 70, 8-15.

SPRITZ, N. and MISHKEL, M. A. (1969). Effects of dietary fats on plasma lipids and lipoproteins: an hypothesis for the lipidlowering effect of unsaturated fatty acids. J. Clin. Invest. $48,78-86$

STEINBERG, D. (1972). Phytanic acid storage disease: Refsum's syndrome. In: The metabolic basis of inherited disease, 4th edition, (Stanbury, J. B., Wyngaarden, J. B. and Fredrickson, D. S., eds.). McGraw-Hill, New York, pp. 688-706.

TALL, A. R. and SMALL, D. M. (1978). Plasma high density lipoproteins. New Engl. J. Med. 299, 1232-1236.

YAO, J. K., ELLEFSON, R. D. and DYCK, P. J. (1976). Lipid abnormalities in hereditary neuropathy: Part I. Serum nonpolar lipids. J. Neurol. Sci. 29, 161-175. 